Proceeding

\title{
Design and synthesis of new amino acid-based ionic liquids as surfactants ${ }^{\dagger}$
}

\author{
Verónica Fernández-Stefanuto ${ }^{1}$, Pedro Verdía ${ }^{1}$ and Emilia Tojo ${ }^{1, *}$ \\ ${ }^{1}$ Faculty of Chemistry, University of Vigo, Marcosende, As Lagoas, 36210-Vigo, Spain; \\ *etojo@uvigo.es; phone.: +34-986-812290 \\ +Presented at the 21st International Conference on Synthetic Organic Chemistry, online, 1-30 November 2017.
}

\begin{abstract}
The design and synthesis of five proline amino acid-based ionic liquids with potential application as surfactants is reported. The structures of the cations and anions were selected looking for water solubility, low toxicity and low viscosity, as well as high biodegradability and high thermal stability. The synthesis was carried out by esterification and direct quaternization with a suitable alcohol, and later anion exchange by a metathesis reaction. Four of them, [ $\left.{ }^{\mathrm{n}} \mathrm{C}_{4} \mathrm{Pro}\right][\mathrm{DS}],\left[{ }^{2} \mathrm{C}_{4} \mathrm{C}_{8}\right.$ Pro][DS], $\left[{ }^{\prime} \mathrm{C}_{10} \mathrm{C}_{14}\right.$ Pro] [DS], and [i $\mathrm{C}_{4}$ Pro][DBS], were not previously described in literature and three of them, $\left[{ }^{n} \mathrm{C}_{4}\right.$ Pro] $[\mathrm{DS}],\left[{ }^{\mathrm{i}} \mathrm{C}_{4} \mathrm{Pro}\right][\mathrm{DS}]$ and $\left[\mathrm{i}_{4} \mathrm{Pro}\right][\mathrm{DBS}]$, showed favourable water solubility. Finally, a stability study to determine their resistance to hydrolysis, was carried out.
\end{abstract}

Keywords: ionic liquids; surfactants; amino acids; water solubility

\section{Introduction}

Surfactants are compounds that contain groups with opposite solubility (hydrophobic and hydrophilic). According to the nature of the hydrophilic group, the surfactant molecules can be classified as anionic, cationic, amphoteric and non-ionic. There is structural similarity between surfactants and ionic liquids (ILs) structures when a long alkyl chain is introduced into the cation, the anion, or both [1]. This makes possible replacing conventional surfactants with ILs, reducing risks of toxicity and contamination, as well as introducing all other advantages of ILs, such as negligible vapour pressure and high solubility in different solvents; therefore, they have been used in several areas of chemistry with success [2].

In this work, a series of ILs were selected to be used as surfactants. Their structures were designed aiming water solubility, low toxicity and viscosity, as well as high biodegradability and high thermal stability. Due to the low toxicity of amino acids, cations derived from L-proline (1) introducing different alkyl chains on the ester functional group were chosen [3]. These cations allow direct nitrogen quaternization and also simple variations on the side chain. Taking into account the known applications of dodecylsulfate and dodecylbenzenesufonate salts as surfactants, dodecylsulfate [DS] and dodecylbenzenesufonate [DBS], were selected as anions. 


\section{Materials and Methods}

Chemical reactants and solvents were supplied by Sigma Aldrich and Acros-organics. All solvents were distilled prior to use.

The glass material employed in the synthetic reactions was dried in an oven at $60^{\circ} \mathrm{C}$ during $24 \mathrm{~h}$ before its use. The evolution of the reactions was monitored by thin layer chromatography (t.l.c.) employing silica-gel sheets (Merck, TLC Silica gel $60 \mathrm{~F}_{254}$ ). A solution of $\mathrm{CH}_{2} \mathrm{Cl}_{2} / \mathrm{MeOH}(20 \%)$ was employed as eluent.

Spectroscopic data were provided by the Center of Scientific-Technological Support to Research (CACTI) of the University of Vigo. ${ }^{1} \mathrm{H}$ and ${ }^{13} \mathrm{C}$ NMR spectra were recorded on a BRUKER ARX 4CO spectrometer at 400.1621 $\left({ }^{1} \mathrm{H}\right)$ and $100.6314\left({ }^{13} \mathrm{C}\right) \mathrm{MHz}$, respectively. $\mathrm{CDCl}_{3}$ (ACROS Organics, 99.6+ atom \%D) was employed as deuterated solvent as received from the supplier.

\section{Results and Discussion}

\subsection{Synthesis}

The synthesis of four amino acid-base ILs was carried out through esterification and direct quaternization of L-proline (1) with a suitable alcohol, and later anion exchange by a metathesis reaction with sodium dodecylsulfate. The general synthetic procedure as well as ILs acronyms and chemical structures are shown in Figure 1.

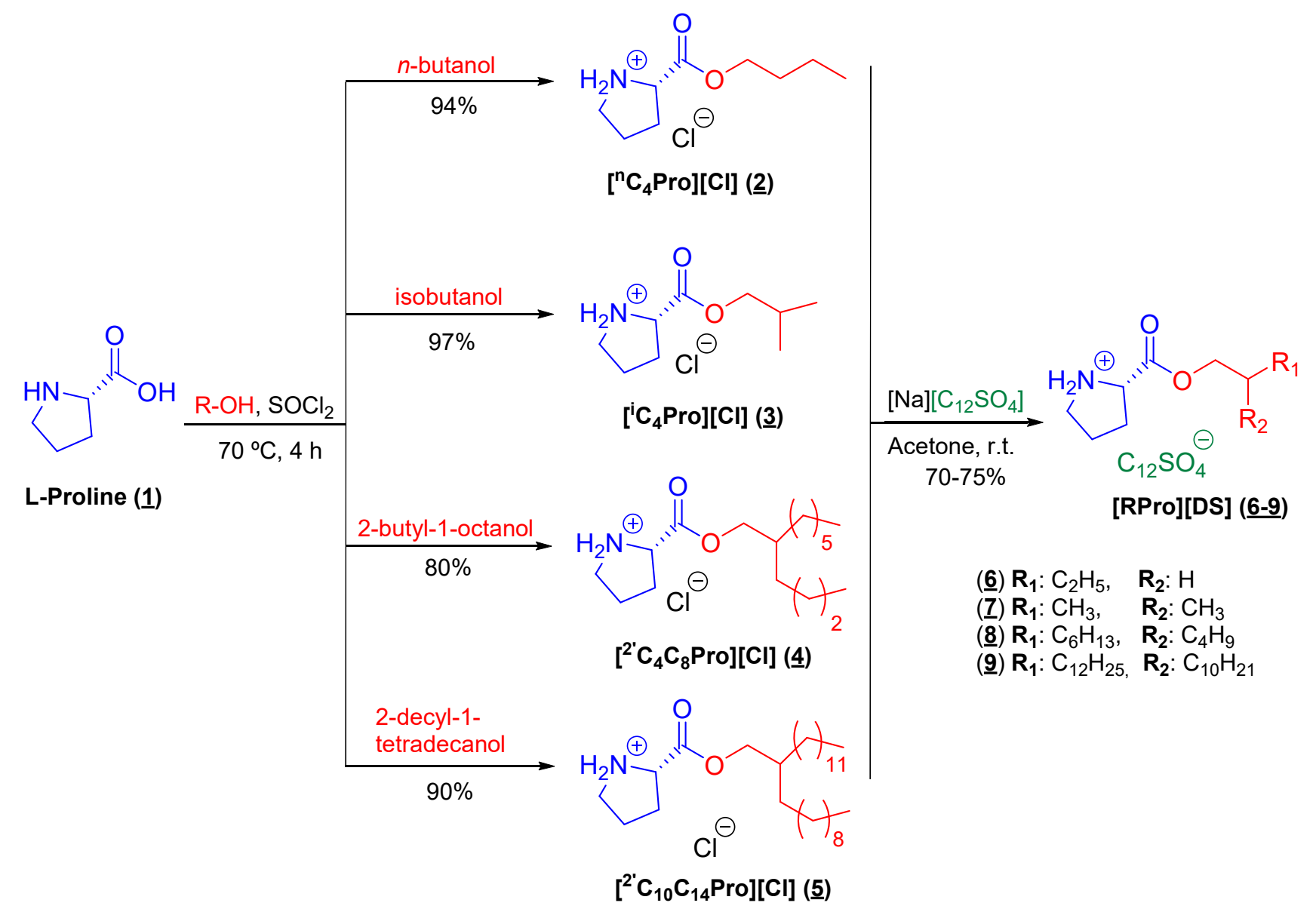

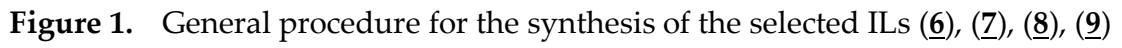


While the ILs with short alkyl chains, $\left[{ }^{[} \mathrm{C}_{4} \operatorname{Pro}\right][\mathrm{DS}](\underline{\mathbf{6}})$ and $\left[{ }^{[} \mathrm{C}_{4} \mathrm{Pro}\right][\mathrm{DS}](\underline{\mathbf{7}})$, shown to be water soluble, those with long alkyl chains, $\left[{ }^{2} \mathrm{C}_{4} \mathrm{C}_{8} \operatorname{Pro}\right][\mathrm{DS}](\underline{\mathbf{8}})$ and $\left[{ }^{\prime} \mathrm{C}_{10} \mathrm{C}_{14} \operatorname{Pro}\right][\mathrm{DS}](\underline{\mathbf{9}})$, gave two phases when mixed with water.

The structures of all synthesized ILs were confirmed by ${ }^{1} \mathrm{H}$ and ${ }^{13} \mathrm{C}$ NMR spectroscopy as well as low and/or high MS spectrometry. The structure of $\left[{ }^{[} \mathrm{C}_{4} \mathrm{Pro}\right][\mathrm{DS}](\underline{7})$, the only IL previously described, was also confirmed by comparison with literature data [3].

\subsection{Stability test}

Though previously reported data of $\left[{ }^{i} \mathrm{C}_{4} \mathrm{Pro}\right][\mathrm{DS}]$ ( $\underline{7}$ ) [3], showed a high thermal stability (onset temperature 280 $\left.{ }^{\circ} \mathrm{C}\right)$, some decomposition was observed when dissolved in water after several weeks. In order to know the decomposition process, a water solution of the IL was heated at $40{ }^{\circ} \mathrm{C}$ and $100{ }^{\circ} \mathrm{C}$ for some days (Table 1).

The ${ }^{1} \mathrm{H}$ NMR spectra showed that when heating $\left[{ }^{i} \mathrm{C}_{4} \mathrm{Pro}\right][\mathrm{DS}](\underline{7})$ in the presence of water the ester group undergoes hydrolysis obtaining protonated proline [4], dodecylsulfate acid and releasing isobutyl alcohol (Figure 2). Liquid-liquid extraction with $\mathrm{CH}_{2} \mathrm{Cl}_{2}$ allowed the isolation of dodecylsulfate acid and protonated proline in the organic and aqueous phases respectively.

When heated at $40{ }^{\circ} \mathrm{C}$ for four days in water (entry 2), only a partial decomposition was observed; but when temperature was raised to $100^{\circ} \mathrm{C}$, partial decomposition is already produced after 1 day (entry 3 ) and a complete hydrolysis after 4 days (entry 4 ).

Table 1. Decomposition of $\left[{ }^{i} \mathrm{C}_{4} \mathrm{Pro}\right][\mathrm{DS}](\underline{7})$ and $\left[{ }^{i} \mathrm{C}_{4} \mathrm{Pro}\right][\mathrm{DBS}](\underline{\mathbf{1 0}})$ at different temperatures when heating in water

\begin{tabular}{ccccc}
\hline Entry & IL & Temperature $\left({ }^{\circ} \mathrm{C}\right)$ & Days & Decomposition \\
\hline 1 & {$\left[{ }^{i} \mathrm{C}_{4}\right.$ Pro $][\mathrm{DS}]$} & 40 & 1 & No \\
2 & {$\left[{ }^{\mathrm{C}} \mathrm{C}_{4}\right.$ Pro $][\mathrm{DS}]$} & 40 & 4 & Partial \\
3 & {$\left[{ }^{\mathrm{C}} 4\right.$ Pro $][\mathrm{DS}]$} & 100 & 1 & Partial \\
4 & {$\left[{ }^{\mathrm{i}} \mathrm{C}_{4}\right.$ Pro $][\mathrm{DS}]$} & 100 & 4 & Complete \\
5 & {$\left[{ }^{\mathrm{C}} 4 \mathrm{C}_{4}\right.$ Pro $][\mathrm{DBS}]$} & 100 & 5 & Partial \\
\hline
\end{tabular}

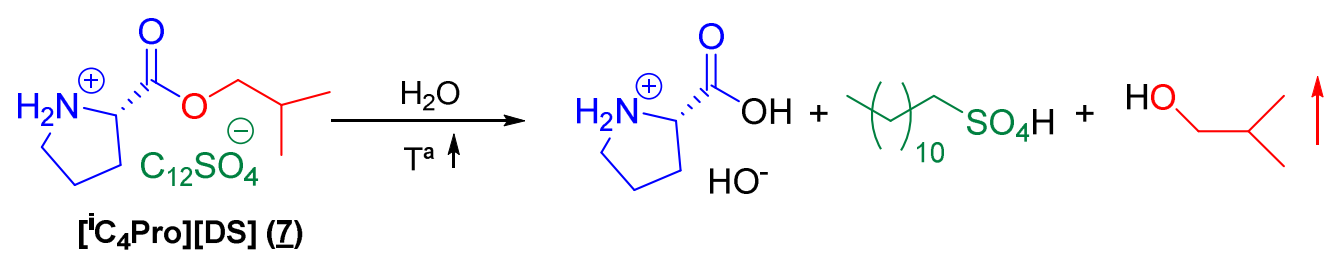

Figure 2. Hydrolysis process of $\left[{ }^{[} \mathrm{C}_{4} \mathrm{Pro}\right][\mathrm{DS}](\underline{7})$

Due to the known general high stability of ILs derived from dodecylbenzenesulfonate anions [5], [ ${ }^{i} \mathrm{C}_{4}$ Pro][DBS] $(\underline{\mathbf{1 0}})$ was also synthesized. Dodecylbenzenesulfonate anion was introduced by treatment of $\left[{ }^{i} \mathrm{C}_{4} \mathrm{Pro}\right][\mathrm{Cl}](\underline{3})$ with

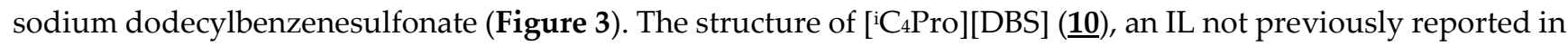
the bibliography, was confirmed by ${ }^{1} \mathrm{H}$ and ${ }^{13} \mathrm{C}$ NMR spectroscopy as well as low MS spectrometry. 
$\left[{ }^{i} C_{4}\right.$ Pro] $[D B S](\underline{\mathbf{1 0}})$ was also found to be water soluble. The decomposition test in the presence of water at $100{ }^{\circ} \mathrm{C}$ with this IL showed partial decomposition after 5 days (Table 1, entry 5).

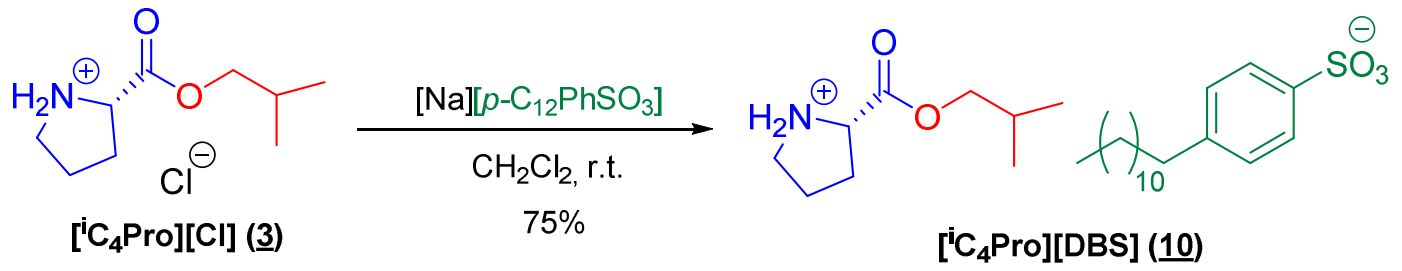

Figure 3. Synthesis of $\left[{ }^{\mathrm{i}} \mathrm{C}_{4} \mathrm{Pro}\right][\mathrm{DBS}](\underline{\mathbf{1 0}})$ from $\left[{ }^{\mathrm{i}} \mathrm{C}_{4} \mathrm{Pro}\right][\mathrm{Cl}](\underline{\mathbf{3}})$

\section{Conclusions}

Five different proline amino acid-based ILs, designed to present water solubility, low toxicity, low viscosity and high biodegradability, were synthesized to be used as surfactants. Four of them, $\left[{ }^{\mathrm{n}} \mathrm{C}_{4} \mathrm{Pro}\right][\mathrm{DS}](\underline{\mathbf{6}}),\left[{ }^{\prime} \mathrm{C}_{4} \mathrm{C}_{8} \mathrm{Pro}\right][\mathrm{DS}]$ $(\underline{\mathbf{8}}),\left[{ }^{\prime} \mathrm{C}_{10} \mathrm{C}_{14} \operatorname{Pro}\right][\mathrm{DS}](\underline{\mathbf{9}})$, and [i $\left.\mathrm{C}_{4} \mathrm{Pro}\right][\mathrm{DBS}](\underline{\mathbf{1 0}})$, were not previously described in bibliography and three of them, $\left[{ }^{\mathrm{n}} \mathrm{C}_{4} \mathrm{Pro}\right][\mathrm{DS}](\underline{\mathbf{6}}),\left[{ }^{\mathrm{i}} \mathrm{C}_{4} \mathrm{Pro}\right][\mathrm{DS}](\underline{\mathbf{7}})$ and $\left[{ }^{\mathrm{i}} \mathrm{C}_{4} \mathrm{Pro}\right][\mathrm{DBS}](\underline{\mathbf{1 0}})$, showed favourable water solubility.

The resistance to hydrolysis of $\left[{ }^{i} \mathrm{C}_{4} \mathrm{Pro}\right][\mathrm{DS}](\underline{\mathbf{7}})$ and $\left[{ }^{\mathrm{i}} \mathrm{C}_{4} \mathrm{Pro}\right][\mathrm{DBS}](\underline{\mathbf{1 0}})$ was also studied. Different degrees of decomposition were observed when these ILs were heated in water at different temperature and time. When heated at $100{ }^{\circ} \mathrm{C},\left[{ }^{i} \mathrm{C}_{4} \operatorname{Pro}\right][\mathrm{DS}](\underline{7})$ showed partial degradation after 1 day while it was completely hydrolysed after 4 days. [ ${ }^{i} \mathrm{C}_{4}$ Pro][DBS] (10) showed to be more stable, giving only partial degradation after 5 days. Future work designing new surfactant proline amino acid-based ILs introducing other functional groups to avoid hydrolysis is needed.

Acknowledgments: We acknowledge the Xunta de Galicia (ED431D 2017/06) for financial support.

Author Contributions: E. Tojo conceived and designed the experiments; V. Fernández-Stefanuto and P. Verdía performed the experiments and analyzed the data; the three authors contributed to wrote the proceeding.

Conflicts of Interest: The authors declare no conflict of interest.

\section{References}

1. Singh, G.; Singh, G.; Zhang, S.; Kang, T.S. Micellization Behavior of Surface Active Ionic Liquids Having Aromatic Counterions in Aqueous Media. J. Phys. Chem. B, 2016, 120, 1092-1105, DOI:10.1021/acs.jpcb.5b09688.

2. Plechkova, N.V.; Seddon, K.R. Application of ionic liquids in the chemical industry. Chem. Soc. Rev., 2008, 37, 123-150, DOI:10.1039/B006677J.

3. Trivedi, T. J.; Srinivasa, R. K.; Singh, T.; Kumar, M. S.; Sutradhar, N.; Panda, A. B.; Kumar, A. Task-Specific, Biodegradable Amino Acid Ionic Liquid Surfactants. ChemSusChem, 2011, 4, 604-608, DOI: 10.1002/cssc.201100065.

4. Dong, L.; He, L.; Tao, G.H.; Huang, M.; Hu, C. Theoretical Enthalpies of Formation of [AA]X and [AAE]X Type Amino Acid Ionic Liquids. J. Chem. Eng. Data, 2013, 58, 1176-1185, dx.doi.org/10.1021/je301285c.

5. Rao, K. S.; Gehlot, P.S.; Gupta, H; Drechsler, M.; Kumar, A. Sodium Bromide Induced Micelle to Vesicle Transitions of Newly Synthesized Anionic Surface Active Ionic Liquids Based on Dodecylbenzenesulfonate. J. Phys. Chem. B, 2015, 119, 4263-4274, DOI:10.1021/jp512805e.

(1) 2017 by the authors. Submitted for possible open access publication under the terms and conditions of the Creative Commons Attribution (CC BY) license (http://creativecommons.org/licenses/by/4.0/). 